\title{
Natureza e paisagem: o espaço no cinema de Naomi Kawase
}

\author{
Larissa Veloso Assunção ${ }^{1}$
}

\section{Introdução}

A filmografia de Naomi Kawase, cineasta japonesa contemporânea nascida na pequena cidade de Nara, engloba obras tanto ficcionais quanto documentais e apresenta uma particularidade no que se refere à apresentação dos espaços, sejam eles os ambientes domésticos, os espaços da cidade ou aqueles da natureza. Seus filmes versam principalmente sobre os temas familiares, cotidianos, "menores". São os pequenos causos rotineiros, nada há neles de exagerado, de melodramático - embora a aproximação com o melodrama se dê em algumas de suas obras ficcionais como Sabor da vida (An, 2015) ou Esplendor (Hikari, 2017). É a vida que se faz presente diante da câmera - seja ela recriada nas ficções ou aquela registrada na urgência do instante, como em seus documentários caseiros. É nesse sentido que estudos sobre sua obra geralmente reverberam em análises sobre o autorretrato. É este o caso, por exemplo, da leitura de Oliveira e Codato (2017), ao apontar que

Kawase investiga a própria vida na companhia de uma câmera, (re)visitando arquivos do passado de sua família, disparando novos acontecimentos, imbricando a potência performativa de seu corpo ao corpo das imagens e (re)criando um mundo ao deslocar reminiscências no tempo (Oliveira e Codato 2017, 136).

Outro foco de análise predominante é aquele que discute a dimensão corpórea de seu cinema, como faz Erly Vieira Jr. (2014) ao pensar a obra de Kawase a partir da noção de cinema de fluxo, em que a própria câmera, segundo o autor, funcionaria como uma espécie de corpo. Um cinema que se dá a partir de um "olhar microscópico sobre o espaço-tempo cotidiano e por uma experiência afetiva pautada pela presença de uma sensorialidade multilinear e dispersiva" (Vieira Jr. 2014, 112). Ou ainda autoras como Carla Maia e Patrícia Mourão (2011), que discorrem sobre a dimensão sensível da materialidade das imagens de Kawase num olhar que também se debruça sobre a representação do corpo em seus filmes e aponta já para uma relação íntima deste corpo com a natureza, com o espaço ao redor.

${ }^{1}$ Universidade Federal do Pernambuco, Av. Prof. Moraes Rego, 1235, Cidade Universitária, Recife, CEP 50670-901, Pernambuco, Brasil. 
Sabemos muito pouco do (...) passado [dos personagens], de suas histórias pregressas, marcadas inevitavelmente pela perda (...). É um acúmulo de falta. A grande operação da cineasta é fazer com que os signos dessa falta e desse acúmulo coincidam com os índices da natureza: a sutil violência do vento nas folhas das árvores, a estridência do som dos insetos (Maia, Mourão 2011).

Tendo em vista esses olhares atentos à obra de Kawase, este trabalho pretende se debruçar sobre dois filmes ficcionais da cineasta - Floresta dos lamentos (Mogari no Mori, 2007) e O segredo das águas (Futatsume no Mado, 2014) -, a partir de um olhar voltado para a relação com o espaço, análise esta que se dará a partir de um viés ecocrítico. Cabe, portanto, um breve preâmbulo sobre essas questões.

\section{A abordagem ecocrítica}

Se o pensamento ocidental cartesiano nos colocou epistemologicamente diante de uma posição dualista de mundo concebendo o humano como separado de seu entorno e como um ser que, por ser dotado de racionalidade, se distinguia de maneira superior às demais espécies -, existe por outro lado uma concepção crítica que, na contramão desse dualismo, irá proporoutros modos de conceber a relação do ser humano com a natureza e com o não humano. Nesse sentido, a ecologia se revela como um campo de saber em que as questões da natureza se fazem prioritárias, na busca por alternativas que minimizem os impactos das ações humanas nos ecossistemas, por exemplo, e concebendo as instâncias não humanas de forma não hierárquica. Se a ecologia, contudo, diz respeito mais diretamente a áreas como as Ciências da Natureza, a ecocrítica se mostra um campo de estudos na área das Humanidades como uma alternativa acadêmica para pensar as obras artísticas a partir dessa outra concepção epistemológica, buscando reduzir as hierarquias entre seres humanos e natureza, e pensar as maneiras pelas quais se dá a representação dessas duas instâncias nas obras de arte. Como resume Willoquet-Maricondi, "a ecocrítica nos ajuda a identificar trabalhos que tenham uma orientação ambiental" (WilloquetMaricondi 2010, 2; tradução nossa).

Inicialmente a ecocrítica surge na teoria literária no final do século XX, em que os livros eram analisados sob a perspectiva da representação da natureza e das relações entre o humano e o não humano. Posteriormente outros campos de saber dentro das Humanidades irão se utilizar do pensamento ecocrítico, como é o caso dos estudos fílmicos, para pensar as obras a partir de uma perspectiva ecológica. Nesse sentido, como apontam Pick e Narraway (2013), as possibilidades de análise a partir da questão ambiental se mostram muito diversas, visto que englobam não apenas "a inscrição cinematográfica do mundo, mas (...) ambientes fílmicos e microambientes, e (...) o cinema como uma relação ambiental" (2013, 4; tradução nossa). A ecocrítica, portanto, se revela como um campo interdisciplinar, visto que a relação entre ser humano e mundo está 
atravessadas por questões outras ligadas a gênero, classe e raça, por exemplo.

Uma das questões que norteia as análises a partir do viés ecocrítico é a que se pergunta: "como as mudanças na representação da natureza refletem mudanças nas concepções culturais da natureza?" (Willoquet-Maricondi 2010, 20; tradução nossa). Se é preciso cada vez mais pensar as ações humanas dentro de uma perspectiva ecológica e de um olhar para a natureza que não a conceba apenas como um outro, refletir sobre a dimensão política do pensamento ecológico, por outro lado, envolve não apenas as ações humanas sobre a natureza, mas a representação cultural que se faz dela. Em outras palavras, a ecocrítica analisa as maneiras pelas quais é representada a relação entre humano e não humano nos produtos culturais, buscando um olhar para as questões estéticas e éticas envolvidas nessa representação. Como pontuam Pick e Narraway (2013), "compartilhamos uma crença comum no significado do mundo não humano para o trabalho de estudos de cinema" (2013, 10; tradução nossa). É diante disso, portanto, que este trabalho pretende analisar os filmes da cineasta Naomi Kawase a partir da perspectiva da ecocrítica, atentando para o modo como a natureza é trazida em sua obra e na maneira como se dá a relação entre o ser humano e o espaço a seu entorno.

\section{Natureza e paisagem}

Filmados em $8 \mathrm{~mm}$ e $16 \mathrm{~mm}$, os registros documentais de Naomi Kawase se voltam principalmente ao espaço doméstico de sua casa, do jardim, da relação com sua tia avó, tudo isso num tom marcado pela intimidade. Em suas ficções predomina um olhar sensível com relação aos espaços - seja a casa, a paisagem natural, as ruas, a cidade. Embora não se pretenda aqui cair num essencialismo, acreditamos que algo da visão oriental de mundo reverbera na maneira com que Kawase concebe a natureza e a paisagem em seus filmes e, acima de tudo, a relação dos personagens com esse entorno. Há uma espécie daquele sentimento que o geógrafo sino-americano Yi-Fu Tuan chama de topofilia, definindo o conceito como "o elo afetivo entre a pessoa e o lugar ou ambiente físico” (Tuan 1980, 5).

Como nos aponta Madeira (2013) ao discorrer sobre as conexões entre a perspectiva Zen de mundo e o cinema de Kawase, o autor diz que "o zen transcende a filosofia clássica ao pressupor uma visão de mundo que está acima dos binarismos da lógica racionalista, isto é, a distinção sujeito-objeto" $(2013,8)$. Ao contrário disso, há uma concepção mais integralista dos termos dessa relação. Humano e nãohumano são concebidos como interdependentes e é a partir disso, portanto, que este trabalho pretende se debruçar. De que maneira seus filmes podem ser entendidos dentro de uma perspectiva crítica ecológica? Um dos caminhos pensados para essa reflexão, portanto, é analisá-los a partir das noções de natureza e paisagem, buscando de que maneira isso se articula em sua obra e, assim, de que forma se dá a relação entre os personagens e seu entorno. 
Pensar nos conceitos de natureza e paisagem na análise de filmes, portanto, é levar em conta a dimensão similar e ao mesmo tempo distinta entre os termos. Se a noção de natureza parece dizer respeito a algo que independe da figura humana, visto que pode ser compreendida como o conjunto de elementos de um ecossistema: árvores, bichos, montanhas, rios, por exemplo; o conceito de paisagem, ao contrário, é mais facilmente compreendido a partir de um ponto de vista, pelo fato de que, para existir paisagem, pressupomos antes um sujeito que olha e cujo olhar empreende um determinado recorte do espaço. Isso nos remonta, portanto, à discussão proposta por Anne Cauquelin (2007) ao discutir sobre a gênese daquilo que se entende como paisagem - não apenas seu surgimento enquanto gênero autônomo nas artes, como é datado do século XVII na pintura holandesa, por exemplo, mas buscando a origem da nossa percepção mesma da paisagem.

Nesse sentido, a autora retoma textos clássicos da antiguidade e nos revela: não há, no mundo antigo, nada que se aproxime do que chamamos, entendemos e vemos como paisagem. Descrições do mundo natural, ao contrário, são abundantemente encontradas em textos de Horácio e Virgílio, por exemplo. Em que diferem, então, as noções de paisagem e natureza? Para além de uma questão técnica da pintura na Europa renascentista, em que se viu emergir, entre autores como Claude Lorrain e Nicolas Poussin, a paisagem não mais como cenário para ações e eventos, mas enquanto motivo principal das obras, a discussão de Cauquelin se aproxima da noção de Lefebvre que diz que "o nascimento da paisagem deve realmente ser entendido como o nascimento de uma maneira de ver" $(2006,27)$. Ou, como diz o poeta e ensaísta Yves Bonnefoy, citado por Besse, "a paisagem começa na arte com as primeiras angústias da consciência metafísica" (2006, viii). Trata-se, portanto, de certo modo de ver e estar no mundo que se modifica na passagem da Idade Média ao Renascimento, ligado a uma perda do sentimento de totalidade e de pertencimento com relação a um todo, momento em que "o sentimento de pertencer à generosa presença daquilo que é, é substituído então por uma contemplação à distância do mundo" (Besse 2006, viii). Dessa maneira, é toda uma dinâmica sensível do olhar e do estar no mundo que se modifica. Não haveria paisagem, portanto, sem que nossa própria maneira de ver concebesse aquilo que vemos em termos de paisagem.

A descrição da natureza, na Antiguidade Clássica, diverge de nossa atual concepção do termo. Ora, é que a descrição da natureza, nos gregos e romanos, era uma "descrição da ordem do discurso, não da sensibilidade" (Cauquelin 2007, 51). Ou seja, quando Horácio elogia a "casa que se abre para os campos ao longe" (Horácio apud Cauquelin 2007, 63), a autora nos diz que o que está em questão é o discurso sobre o campo, o elogio diz respeito "à calma dos espaços agrestes", que eram valorizados enquanto lugares de sabedoria. Não se tratava, portanto, de uma "visão sensível" do espaço. Este recorte sobre o espaço a partir de um ponto de vista, segundo Cauquelin, aparece com o surgimento da perspectiva. O que se aproxima também 
da discussão proposta por Ivakhiv (2013) quando o autor diz que "essa perspectiva agiu, na verdade, como parteira do nascimento da modernidade - uma modernidade que, segundo o filósofo Heidegger, nos deu 'o mundo como imagem'" (2013, 3; tradução nossa). Se o surgimento da perspectiva nos oferece esse "mundo como imagem", outros autores, contudo, vão conceber a paisagem não apenas como superfície a ser contemplada a partir de um olhar distanciado, mas enquanto instância vivenciada por dentro.

É o caso do antropólogo Tim Ingold (1993), por exemplo, que propõe uma concepção de paisagem que não a entende apenas em oposição ao conceito de natureza. Ao contrário, ele busca diminuir o antagonismo que esses dois termos operam entre a noção de natural versus cultural. É o caso do conceito de taskscape (tarefagem) que o autor nos apresenta (ver também Cesar de Siqueira Castanha neste número da Aniki), por exemplo:

É a todo o conjunto de tarefas, em seu entrelaçamento mútuo, que me refiro ao conceito de taskscape. Assim como a paisagem é uma matriz de recursos relacionados, então - por analogia - a taskscape é uma matriz de atividades relacionadas. E, como a paisagem, é qualitativa e heterogênea: podemos perguntar de uma taskscape, como de uma paisagem, como ela é, mas não quanto dela existe. Em suma, a taskscape está para o trabalho como a paisagem está para a terra. (Ingold 1993, 158; tradução nossa).

Ao buscar uma noção de paisagem em relação à figura humana, ao trabalho com a terra, por exemplo, Ingold discorda da distinção que geralmente se faz entre natureza e humanidade e, em contrapartida, apresenta um conceito de paisagem atrelado à noção de tarefagem - $\mathrm{e}$ de uma relação até mesmo temporal entre as atividades humanas e as próprias temporalidades cosmológicas da terra, como os ciclos atmosféricos e rochosos, por exemplo, revelando quase uma ausência de fronteiras entre o humano e o não humano. Essa concepção da paisagem a partir de Ingold se mostra pertinente para uma análise dos filmes de Naomi Kawase. Em sua obra, a representação do espaço não é a de nos oferecer o mundo unicamente "como imagem". Menos do que a contemplação à distância do mundo, a paisagem é vivenciada a partir de dentro, trazida cada vez mais para perto do corpo, numa dimensão sensorial desse contato e das emoções que ele traz.

Uma das perguntas que norteia este artigo, portanto, é a seguinte: de que maneira o cinema de Naomi Kawase concebe a natureza a partir de uma comunhão com o humano e não apenas como superfície a ser contemplada à distância? Como corpus de análise, portanto, este trabalho irá se debruçar mais especificamente sobre os filmes Floresta dos lamentos e $O$ segredo das águas e, com isso, refletir sobre a dinâmica dessas relações entre humano, natureza e paisagem a partir destes espaços centrais nos dois filmes: a floresta e o mar, respectivamente. 


\section{A sensorialidade do espaço}

Há uma predominância, no cinema de Kawase, da dimensão sensível da natureza. Tal sensorialidade surge nos filmes a partir dos sons, da textura da imagem, do movimento de câmera. Nesse sentido, é possível relacionarmos suas escolhas estéticas com o que Laura Marks (2000) chama de visualidade háptica. Este conceito dá conta de um tipo de visualidade no cinema para além do olho. Não importa apenas aquilo que é visto, mas o que é sentido a partir do que se vê. O olhar ganha uma dimensão tátil na medida em que o filme constrói uma sensorialidade em torno do que é visto. Em outras palavras, é um tipo de visualidade em que "os próprios olhos funcionam como órgãos de toque" (Marks 2000, 162; tradução nossa).

De seus filmes documentais às ficções, Kawase sempre se mostra atenta aos detalhes e, principalmente, às sensações evocadas por esse registro. A mão que segura uma fotografia, a tremulação da câmera ao filmar o telefonema a seu pai biológico, os pingos de chuva na janela, frutas em cima da mesa. Os cantos da casa, o jardim, tudo isso ganha uma dimensão afetiva no cinema de Kawase. E se esses registros nos comovem, por mais despretensiosos que aparentem ser, é porque há uma espécie de textura nessas imagens que parecem nos tocar fisicamente. Não se trata apenas do que vemos desenrolar na imagem, mas a maneira pela qual Kawase cria um corpo fílmico sensível e dotado de uma materialidade que nos convida a senti-lo quase que fisicamente. Ao filmar sua tia avó, Kawase aproxima a câmera do rosto, como se a objetiva necessitasse do contato, do toque. $\mathrm{O}$ afeto, em Kawase, está intimamente ligado a essa dimensão sensível de seus filmes. Como aponta Madeira (2013) sobre a obra de Naomi, “esse cinema é (...) carregado de uma visualidade háptica, isto é, uma visão calcada na percepção corporal do mundo. Uma visão que transmite sensações e respostas que são também do corpo" $(2013,3)$. Tal sensorialidade se constrói não apenas na filmagem do espaço doméstico, mas se volta também para o registro dos elementos da natureza.

O segredo das águas (2014) conta a história da vida familiar de Kyoko e Kaito. Eles vivem numa espécie de ilha e, por isso, o mar se apresenta desde o início como dimensão central da narrativa. Ambos são adolescentes em fase de descoberta de questões como o amor, a perda, a morte. Kyoko tem de aprender, aos poucos, a lidar com o fato de que sua mãe está doente e já perto de morrer. A mãe, no entanto, uma espécie de xamã, demonstra a todo momento tranquilidade com relação à partida próxima. Ela constantemente aparece observando a natureza de maneira atenta, sensível. Fecha os olhos, respira fundo, olha através da janela do quarto que dá para uma árvore de mais de quinhentos anos. Há um momento em que ela anda em direção aos inúmeros ramos da árvore que se espraiam pelo quintal da casa. O pai de Kyoko então fala à filha: "nós não vemos nada, mas sua mãe... acho que ela vê algo". Logo nos planos seguintes ela aparece com as mãos esticadas por entre os galhos da árvore, tocando-os de leve (Figura 1). O som é apenas o do vento e ela em silêncio. 


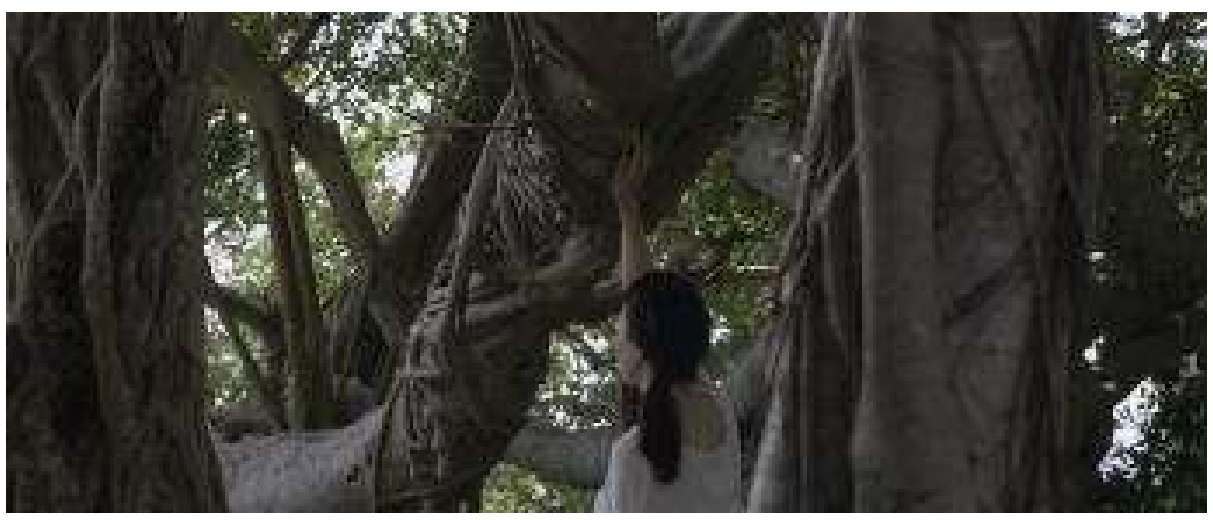

Figura 1: Mãe de Kyoko tocando árvore | (c Naomi Kawase, Kumie.

No momento seguinte, vemos um plano do mar - sem horizonte, apenas a água em movimento. Esse plano revela a superfície marinha, embora pareça também antever toda uma profundidade oculta. O mar não é filmado como paisagem, mas de maneira que pressentimos que há, por detrás da superfície das ondas, toda uma profundeza, um mistério. O que nos remete à fala do Kaito sobre ter medo de surfar: "O mar é assustador. O mar... está vivo". Kawase filma o mar como esse mistério e, acima de tudo, como elemento que contém vida, movimento. Ainda que assustador, como quando o mar leva o corpo do homem tatuado, que provavelmente morreu afogado, o mar também é entendido como instância que possibilita a união com o humano, como quando a personagem fala de seu pai que nem sempre, mas às vezes sim, alcança certa união com o mar quando surfa.

Em Floresta dos lamentos (2007), o filme se volta para a representação da velhice e do processo de superação da perda. Shigeki vive num asilo e sofre ainda com a morte da esposa. Machiko é uma das cuidadoras do local e também está em processo de luto pela perda do filho. Ainda no início do filme, há um momento em que Machiko pega na mão de Shigeki a pedido de uma espécie de monge do local. Ele pergunta a Shigeki se ele sente a energia de Machiko e então o diz: "essa é a sensação de viver. Viver, portanto, é sentir". A câmera foca na mão de Machiko sobre a de Shigeki. No filme de Kawase, o toque mais sutil ou os sons mínimos como o pingar da chuva numa poça d'água e o ruído da floresta são elementos primordiais.

A impressão que seus filmes deixam - e aqui uma sensação pessoal logo após assistir $O$ segredo das águas - é aquela de uma abertura dos sentidos aos pequenos sons e sensações no contato com as coisas cotidianas. É como se o filme nos tivesse apresentado uma vivência de corpo tão cuidadosa e detalhada que nos ficasse a sensação tátil da experiência fílmica, como se o filme nos destravasse os sentidos e permitisse uma percepção mais atenta e presente. "Deste modo, como materialidade, o filme é um corpo que possui a capacidade de afetar, de tocar - uma capacidade tátil" (Lanzoni 2017, 77). É por esse caminho que a filmagem da natureza e das interações entre o humano e seu entorno, na obra de Kawase, se envereda; a 
partir desse registro sensível do contato entre homem e natureza. A cineasta nos apresenta, portanto, registros em que essa interação não nos é apresentada a partir de uma concepção antropocêntrica, mas a partir de uma visão mais ecológica que entende a natureza como dimensão viva, autônoma.

Sobre essa relação entre a experiência fílmica e um tipo de vivência ecológica do espaço, é possível pensarmos a partir do que Giuliana Bruno (2018), em seu livro Atlas of emotion, nos fala a respeito do caráter espacial e arquitetônico do cinema. A autora concebe o espaço como prática e não apenas de maneira estática e, nesse sentido, ela pontua que o percurso pelos espaços, a dinâmica do caminhar, a fragmentação do olhar - tudo que é intrínseco ao se deslocar por um conjunto arquitetônico - também é reivindicado como próprio da espectatorialidade do cinema. Em outras palavras, nos deixamos levar pelos afetos e emoções através das imagens, cidades e paisagens que o cinema nos oferece. Ao contrário do voyeur, "o espectador é antes um voyageur, um passageiro que atravessa um terreno háptico, emotivo” (Bruno 2018, 31; tradução nossa).

É justamente esse percurso háptico que encontramos nos filmes de Kawase. A materialidade das imagens de seus filmes se dá por suas escolhas estéticas. Muitas das cenas são planos-sequência em que a câmera percorre desde os elementos mínimos do lugar até à visão mais ampla, feita em paisagem. Tal "mundo como imagem", no entanto, é a todo momento trazido novamente ao olhar detalhado, próximo. A câmera se aproxima dos galhos se movendo através do vento, ou da superfície da água quando uma gota cai, ou ainda da textura úmida da floresta vista e vivenciada por dentro.

Aqui cabe, portanto, um paralelo com o que Gumbrecht (2010) chama de efeito de presença. O autor alemão reivindica para a área das Artes e Humanidades um pensamento sobre a estética que se dê para além da busca de sentido ou de interpretação, mas de uma análise que se volte para a atmosfera de uma determinada obra, um certo stimmung. De difícil definição, Gumbrecht o traduz como atmosfera, ambiência. Além disso, recorre a termos em outras línguas que o auxiliam na delimitação do conceito. Assim, ele coloca que palavras como mood e climate expressam noções como certo "estado de espírito", algo mais interior - com relação a mood -, e "alguma coisa objetiva que está em volta das pessoas e sobre elas exerce uma influência física" (Gumbrecht 2014, 12), que ele reconhece estar mais próximo do termo climate. Na obra de Kawase, existe um olhar atento a essa atmosfera trazida pelo ambiente, pela natureza. A floresta tem uma dinâmica própria de sensação. Quando mais os personagens percorrem seu interior, mais a claridade do mundo lá fora se esvai. A floresta revela uma dimensão de sombra, de profundeza, ainda que opere também como lugar em que esses personagens reestabelecem um contato com o mundo - seja a dimensão física desse mundo, seja aquela da ordem da espiritualidade, do imaterial. 


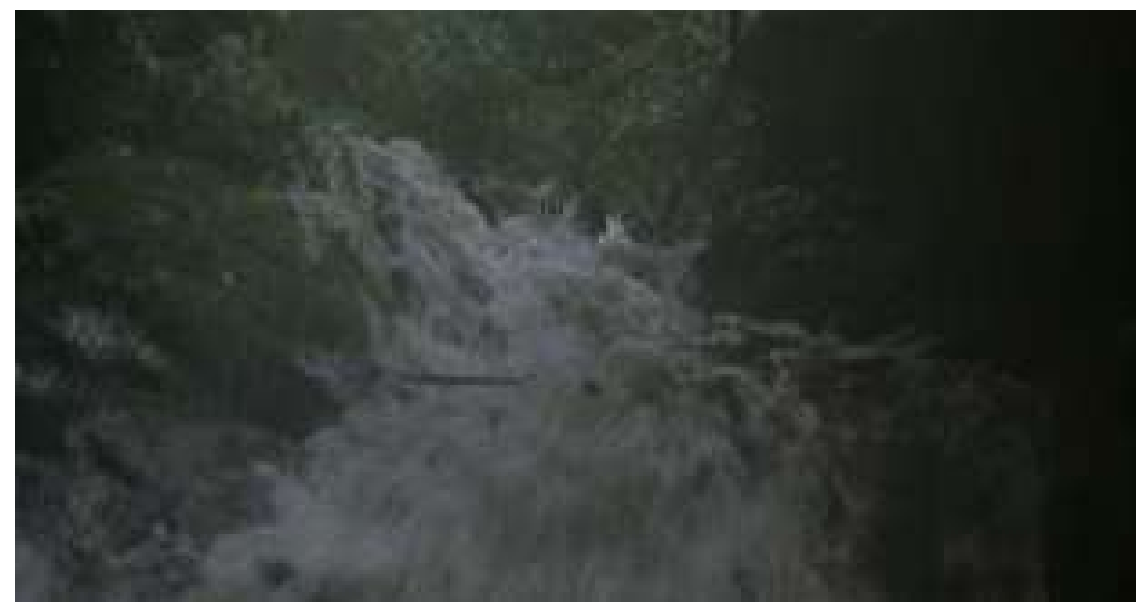

Figura 2: Correnteza do rio no interior da floresta| (c) Naomi Kawase, Kumie

Num certo momento, por exemplo, a chuva é intensa, percebemos a força da correnteza das águas do rio (Imagem 2). Shigeki diz: "a água do rio, que flui constantemente, nunca retorna a sua fonte". O que remete à fala do crítico Kato: "Em todos os níveis da sociedade japonesa, há uma forte tendência de se viver o presente, deixando o passado ser levado pelas águas e confiando o futuro à direção do vento" (Kato 2012, 16). É preciso mesmo que toda a água transborde, corra sem volta. A natureza, em Kawase, não é apenas calma e tranquilidade, mas também revela seus momentos tempestivos e de intensidade. O ambiente natural, no filme, a todo momento se revela enquanto instância de aprendizado, de sabedoria. A fala de Shigeki é exemplo disso na medida em que a natureza se revela como lugar de sabedoria sobre um comportamento humano no mundo. O ser humano entendido aqui não como outro em relação ao espaço natural, mas o ser humano enquanto fazendo parte do que se constitui como natureza. Ou seja, há uma concepção da natureza não como inferior à dimensão racional, mas como estando em relação não hierárquica com o ser humano. Há um respeito para com esse espaço e seus ciclos.

Além disso, tanto em $O$ segredo das águas quanto em Floresta dos lamentos, a natureza parece ser representada como pertencente a um sagrado, há a busca de "registrar a realidade como se fosse um milagre" (Kawase apud Madeira 2013, 7). Essa concepção da natureza como ligada a uma dimensão espiritual já está presente em filmes anteriores da cineasta, como o documentário Céu, vento, fogo, água, terra (2001), no qual ela vai atrás de sua mãe biológica e a questiona sobre o porquê do abandono. O título do filme é a tradução em português do que, originalmente, se chama Kya Ka Ra Ba A - termo que representa os cinco elementos que, segundo o budismo, significariam o mundo composto por tais elementos.

Em sua obra como um todo, as águas, o barulho do vento nas folhas, os pingos de chuva a escorrer pela janela, tudo isso adquire uma dimensão afetiva, sensível - e aqui nos dois sentidos do termo: tanto a sensibilidade do olhar de Kawase sobre o mundo, quanto o 
cinema feito mesmo a partir de uma qualidade sensível. "A imagem háptica se configura como um espaço que induz a uma percepção mais tátil do que visual, que requer uma percepção próxima, com a visão operando quase que pelo toque" (Oliveira 2015, 10). Nesse sentido, portanto, a dimensão sonora do filme se mostra fundamental na criação dessa atmosfera e sensorialidade. Sobre a importância do componente sonoro na percepção da ambiência fílmica, Lanzoni pontua:

O sentido da audição é uma complexa forma de percepção que envolve todo o corpo, ao absorver uma forma de realidade física que nos chega - o som -, assim como o clima atmosférico que envolve nossos corpos e desperta-nos variadas sensações (Lanzoni 2017, 72).

Além disso, há também certa propensão da natureza, da maneira que é retratada nos filmes de Kawase, em esconder mistérios, tempos outros. Como quando o avô de Kyoko, em O segredo das águas, vê a neta caminhando na areia da praia. Ele a chama, inicialmente, por outro nome. Então depois revela: "Por um instante, confundi você com sua bisavó". Ao que acrescenta: "Quando vou para o mar, quando vou para as colinas, quando vou para os campos, sempre a vejo". Nesse sentido, há uma conexão entre a dimensão física do mundo e aquela da imaterialidade, do que não é palpável. É o que nos aponta o comentário a seguir sobre a relação, no cinema, entre essas duas instâncias.

O cinema funciona por representação, portanto, na medida em que pode nos mostrar o mundo ao mesmo tempo em que aponta para seu desaparecimento, o filme torna possível pensar a interação entre o representável e o irrepresentável. (Ivakhiv 2013, 22; tradução nossa).

O mesmo pode ser dito sobre Floresta dos lamentos. Num dado momento, uma senhora do asilo pergunta: "antes de nascermos, quando ainda não existíamos, onde é que estávamos?”. Uma espécie de tentativa de dar conta do ser e estar no mundo, mesmo quando se pensa sobre o tempo anterior ao da existência. O que nos leva a um trecho do livro A poética do espaço, de Bachelard, quando autor escreve sobre o espaço da floresta. Ele se questiona: "mas quem nos dirá a dimensão temporal da Floresta?". Ao que acrescenta: "no vasto mundo do não-eu, o não-eu dos campos não é o mesmo que o não-eu das florestas. A floresta é um antes-de-mim, um antes-de-nós" (Bachelard 2008, 194). Logo após a pergunta, no filme, surge a imagem do interior da floresta. A natureza em Kawase surge como lugar que guarda um passado, uma memória. O que nos remete a Ingold (1993), quando o autor busca aproximar os conceitos de natureza e paisagem:

Perceber a paisagem é, portanto, realizar um ato de recordação, e recordar não é tanto uma questão de invocar uma imagem interna, armazenada na mente, quanto de se engajar perceptivamente com 
um ambiente que está em si mesmo grávido do passado. (Ingold 1993, 152-153; tradução nossa).

Cada vez que Shigeki e Machiko adentram mais a floresta, há uma dimensão desse passado que vem à tona. Num momento, ele diz: "por muito tempo vagueei, agora estou aqui". O aqui da floresta é que possibilita aos dois o processo de cura. O título do filme em japonês é Mogari no Mori. Os créditos finais revelam: etimologicamente Mogari significa tempo e lugar do luto. Ao fim do filme, a personagem Machiko toca uma caixinha de música enquanto olha para cima. Emocionada, ela se deixa levar pelo sentimento quase catártico embora em Kawase tudo se dê sempre de maneira sutil. Nesse momento, os ruídos da floresta compõem a cena. O vento, o farfalhar das folhas, tudo isso traz a floresta não como mero cenário para o desenrolar da ação, mas como a única geografia possível para o processo de cura daqueles personagens (Imagem 3). "Para mim, a família e as relações humanas são muito importantes. Eles representam uma conexão entre passado e futuro. E eu gosto de fazer essa conexão vertical com a natureza" (Kawase, 2013).

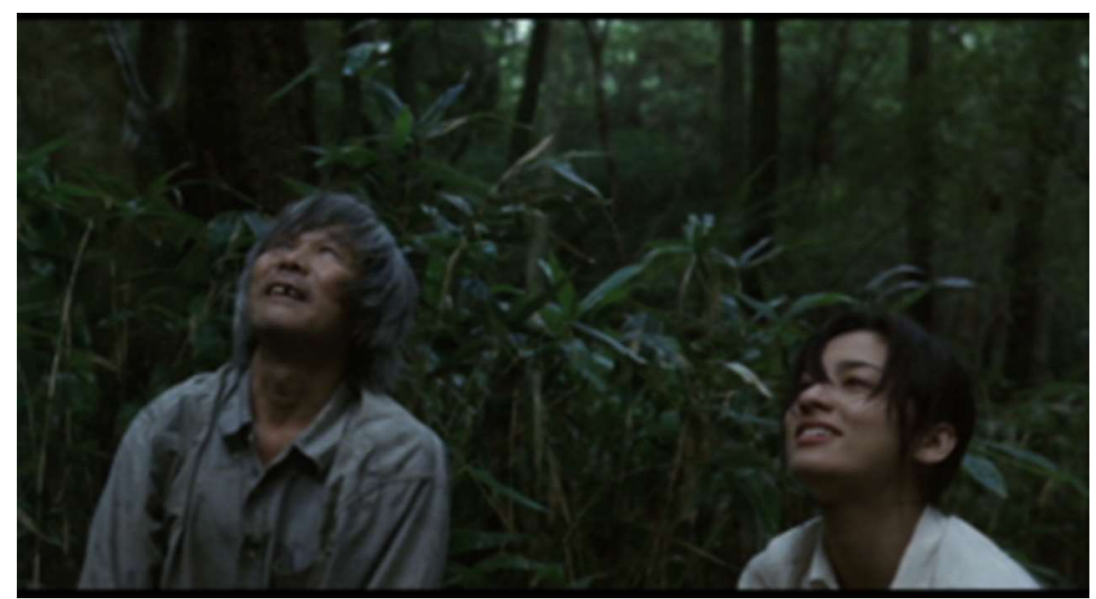

Imagem 3: Shigeki e Machiko no interior da floresta | (c) Naomi Kawase, Kumie

Se é preciso um tempo para vivenciar o luto, a palavra Mogari também reivindica o lugar. E se inicialmente Machiko se sentia apavorada com o imprevisível da floresta - a correnteza que vem de repente, o não saber onde pisar sem cair, por exemplo -, ao fim do filme há uma comunhão entre ela, Shigeki e a natureza. Em Kawase, a floresta e o mar são lugares para além de uma topografia geográfica, há neles uma dimensão espiritual, mística - são lugares que guardam mistérios, profundezas.

Nesse sentido é possível traçar um paralelo entre a representação da natureza em Kawase e o que diz Ivakhiv (2013) sobre os filmes do cineasta russo Tarkovsky. Ao comentar obras como Solaris (1972) - em que o personagem viaja ao planeta chamado Solaris para investigar acontecimentos estranhos na estação espacial -, o 
autor pontua que existe uma zona de indiscernibilidade entre a dimensão da realidade e do sonho. Há um encontro com a "consciência, uma consciência que se mostra ser inter-humana (...) mas que também é sugerida como sendo ecológica (Ivakhiv 2013, 21; tradução nossa). Diferente de filmes como 2001: Uma Odisseia no Espaço (Stanley Kubrick, 1968), em que a corrida espacial é celebratória do quão longe o ser humano e a ciência podem chegar, o filme de Tarkovsky, ao contrário, traz o espaço celeste não como lugar de conquista, mas o apresenta a partir de uma interação entre a consciência e emoções humanas com o oceano e a estação espacial de Solaris.

Essas particularidades do filme de Tarkovsky nos remonta aos dois filmes de Kawase aqui em questão, nos quais prevalece a ideia de uma comunhão entre a paisagem e as sensações dos personagens, como se a natureza e as emoções humanas estivessem conectadas. São realizadores que pensam a paisagem ligada muito mais a uma conexão com o humano do que como algo externo a ele que deve apenas ser usufruído. Se em Tarkovsky, contudo, prevalece o tom mais desencantado, como se uma espécie de perda se fizesse presente nessa relação, em Kawase esse encontro é ainda possível. É na floresta que Shigeki e Machiko encontram um modo de lidar com a perda, assim como é através do mar que Kyoko e Kaito empreendem uma busca de si mesmos. A natureza aparece como esse lugar de afeto, de relação possível com o humano.

Essa conexão se torna ainda mais evidente em algumas cenas, como quando o momento familiar entre Kyoko, sua mãe adoecida e seu pai, por exemplo, é de tranquilidade, carinho e afeto, o vento se mostra tranquilo, o sol ameno, as folhagens se movem levemente através da brisa. Em momento de tensão, no entanto, como quando Kaito se revolta com a mãe por ela ficar com vários homens depois do pai dele, ou quando Kyoko chega a casa em defesa da mãe de Kaito e briga com ele, que sai furioso, as paisagens mostradas são aquelas do mar revolto, do vento forte e cuja atmosfera se revela mais sombria, gélida. Essa alternância entre momentos de tranquilidade, calmaria e instantes de revolta vividos pelos personagens também faz parte das manifestações naturais. O mar é tanto assustador como pacífico. Como se os ciclos da natureza fossem esses de alternância entre opostos e, para ir de um a outro, cada coisa leva seu próprio tempo.

E há ainda o entendimento dessa intensidade da natureza como fonte de aprendizado também, como quando o pai de Kyoko diz: "sabe, Kaito, as ondas consomem todo tipo de coisa. (...) Quando surfamos, temos que lidar com o último estágio de uma onda, que se originou longe da costa. Ao unir-nos com essa onda, por ser seu último instante, ela carrega uma energia incrivelmente poderosa”. Aqui podemos pensar uma conexão entre a intensa energia do último estágio da onda com o último estágio da vida humana também, visto que a mãe de Kyoko está doente e consciente de sua morte próxima. No entanto, ela permanece tranquila, assim como o que o pai de Kyoko fala sobre as ondas: "Então quando você sente essa força, com todo o seu corpo, por um momento, ele se transforma em nada, em 
vazio. De qualquer forma, há a sensação de que tudo, incluindo nós mesmos, permanecemos totalmente serenos". A relação com a natureza não diz respeito apenas ao contato com esse espaço, mas diz da conexão interna com as emoções, com os sentimentos mais profundos.

Assim, nesse registro e observação atenta do cotidiano e da natureza, Kawase nos traz a paisagem através da relação imediata com o humano e da vivência nesse lugar. Em sua obra, as noções de natureza e paisagem, portanto, se aproximam. A natureza é representada como paisagem em muitos momentos, mas é uma paisagem a todo momentos adentrada, vivida a partir de dentro. O que nos leva novamente às considerações de Giuliana Bruno (2018) a respeito da relação entre corpo e espaço fílmico. "Os corpos no espaço projetam campos espaciais, que, por sua vez, projetam corporalidade. Cinema e arquitetura são práticas de representação escrita pelo, e no, mapa corporal" (Bruno, 2018, 89, tradução nossa). Desse modo, o corpo não é visto como separado de seu entorno, mas é justamente o percurso desse corpo no espaço que cria uma espacialidade outra. Em Kawase, é mesmo a partir do entendimento corpóreo do cinema que se dá a representação da natureza. A filmagem do espaço natural é realizada de modo que compreende a correlação entre o percurso do corpo no espaço e a própria imagem dessa espacialidade.

Assim, não há apenas a contemplação estética desse horizonte, visto que os personagens parecem cada vez mais se sentir atraídos a explorar a profundeza desses espaços. Sejam os personagens de Floresta dos lamentos, que ao passar do tempo vão entrando cada vez mais no interior da floresta, sejam Kaito e Kyoko em $O$ segredo das águas, cuja cena final é filmada com a câmera dentro da água (Imagem 4). E se Kyoko antes temia o mar pelo seu caráter vivo e assustador, agora ele se entrega à profundidade desse mistério e das possibilidades que esse contato com as águas traz. Ao fim do filme, o avô de Kyoko diz: "essas crianças ainda não entendem o que se encontra no mar”. Ele continua sendo espaço de segredo, como indica a tradução do título em português.

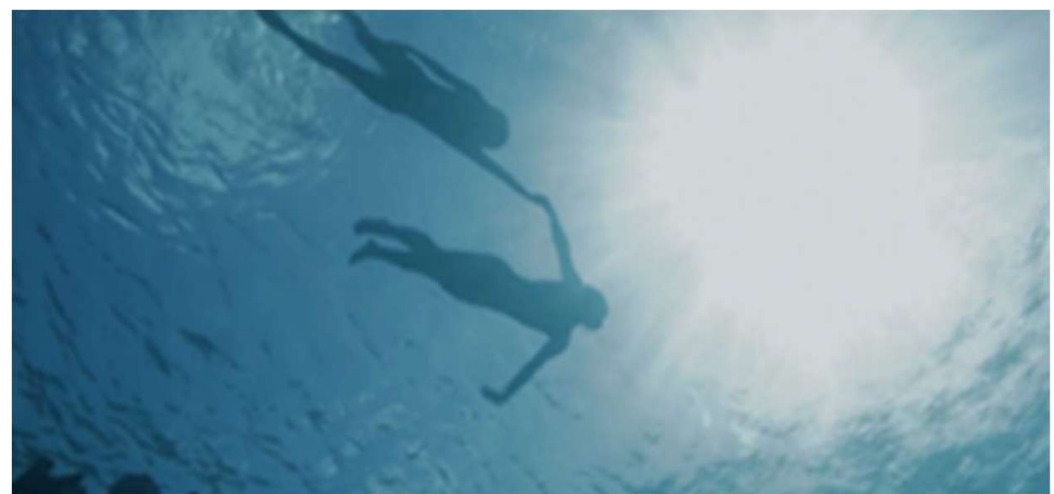

Figura 4: Kaito e Kyoko dentro do mar | (c) Naomi Kawase, Kumie 
Com relação ao entendimento ecológico pensado a partir da noção de gênero, Kawase não cai no simplismo de relacionar a figura feminina como essencialmente mais propensa ao contato íntimo com o mundo natural. Embora no filme $O$ segredo das águas a personagem da mãe de Kyoko seja aquela cuja relação com a natureza é a de maior conexão, não há essa distinção entre a figura feminina relacionada à natureza em oposição à figura masculina mais próxima da ideia de cultura. O filme de Kawase se aproxima do que reivindica Plumwood (2002) para o pensamento crítico ecológico: "nem aceitar a exclusão da mulher da razão, nem aceitar a construção da natureza como inferior" (20; tradução nossa).

Nesse sentido, nem a mulher é retratada como essencialmente mais propensa à relação com a natureza - visão que cairia no reducionismo e, portanto, afastaria a mulher da esfera da razão -, mas também não concebe a natureza como dimensão inferior à racionalidade. Se a personagem da mãe de Kyoko tem essa relação mais desenvolvida é por questões outras e não por uma associação imediata com o gênero. Do mesmo modo, no filme Floresta dos lamentos, ambos os personagens experienciam a floresta como lugar de cura, não há uma concepção essencialista da mulher como estando mais propensa a isso. Kawase rompe, portanto, com o dualismo razão/natureza e, ao contrário, concebe as instâncias humanas e não humanas como correlacionadas, interdependentes.

\section{Conclusão}

A visão ecológica que podemos reconhecer na obra de Kawase, portanto, não se faz no discurso explícito, mas sim na própria forma com que a cineasta empreende seus registros. Não há um apelo direto à urgência das questões ambientais, mas é no modo mesmo de filmar a natureza e a relação do ser humano com esse ambiente que Kawase põe em perspectiva outra postura diante da questão ecológica. Caberia aqui o entendimento de uma política das imagens a partir de Rancière (2012), quando o autor coloca que "não há um real em si, mas configurações daquilo que é dado como nosso real (...). O real é sempre objeto de uma ficção" (74). O autor acredita no potencial político das imagens menos como "arma de combate" mas, ao contrário, no fato que a arte possibilita "desenhar configurações novas do visível, do dizível e do pensável e, por isso mesmo, uma paisagem nova do possível" (Rancière 2012, 100). Se pensarmos nesse potencial político da arte como criadora de mundos possíveis, o filme de Kawase pode ser visto como um cinema que cria essa possibilidade integração com a natureza que é da ordem da troca, do olhar atento e do contato, não apenas uma contemplação à distância ou de uma concepção de natureza apenas utilitária. Estética e política, desse modo, como dimensões indissociáveis.

A natureza em Kawase, portanto, é entendida como dimensão essencial da vida cotidiana. Se prevalecem atualmente certos discursos turísticos de vender a natureza como espaço a ser contemplado durante alguns dias como fuga de uma vida tumultuada 
na cidade, por exemplo, em Kawase a natureza nunca foi afastada do entorno dos personagens, de suas vidas cotidianas na paisagem urbana, no bairro. Em $O$ segredo das águas, a pequena cidade continua lá, e, no entanto, a natureza não é uma dimensão à parte disso. Pelo contrário, as casas parecem se abrir para esse entorno. As grandes janelas dão para as árvores, para as montanhas ao longe. Os sons naturais adentram o espaço doméstico, a exemplo do vento nas folhagens. Em Kawase, portanto, é possível pensarmos uma política das imagens a partir da perspectiva ecológica na medida em que ela traz, em seus filmes, uma relação mais igualitária entre as dimensões humanas e não humanas. Um olhar para a natureza cuja concepção não é a de um antropocentrismo ou de uma concepção binária entre sujeito-objeto, mas, ao contrário, é a de uma integração e interdependência destas duas instâncias: ser humano e natureza.

\section{BIBLIOGRAFIA}

Bachelard, Gaston. 2008. A poética do espaço. São Paulo: Martins Fontes.

Besse, Jean-Marc. 2006. Ver a terra: seis ensaios sobre a paisagem e a geografia. Tradução Vladimir Bartalini. São Paulo: Perspectiva.

Bruno, Giuliana. 2018. Atlas of emotion: Journeys in Art, Architecture, and Film. New York: Verso.

Cauquelin, Anne. 2007. A invenção da paisagem. São Paulo: Martins Fontes.

Gumbrecht, Hans Ulrich. 2012. Atmosfera, ambiência, Stimmung: Sobre um potencial oculto da literatura. Tradução: Ana Isabel Soares. Rio de Janeiro: Contraponto: Ed. PUC-Rio.

———. 2010. Produção de presença: O que o sentido não consegue transmitir. Tradução: Ana Isabel Soares. Rio de Janeiro: Contraponto: Ed. PUC-Rio.

Ingold, Tim. 1993. The temporality of the landscape. World archaeology, v. 25, n. 2, 152-174.

Ivakhiv, Adrian J.. 2013. Ecologies of the Moving Image: Cinema, Affect, Nature. Wilfrid Laurier University Press.

Kato, Shuichi. 2012. Tempo e espaço na cultura japonesa. São Paulo: Estação Liberdade.

Kawase, Naomi. 2013. CONVERSATION - Naomi Kawase: "It is as a human being that I approach my fictions". Entrevista concedida a Benoit Pavan. Disponível em: https://www.festivalcannes.com/en/69-

editions/retrospective/2013/actualites/articles/conversation -naomi-kawase-it-is-as-a-human-being-that-i-approach-myfictions [Acessado em 8 de março de 2019]. 
Lanzoni, Pablo Alberto. 2017. Stimmungen tangíveis: incursões sobre as atmosferas na sala escura. ALCEU - v. 17, n.34, 70-80.

Lefebvre, Martin. 2006. Landscape and film. London; New York: Routledge.

Madeira, Eduardo. 2013. O Corpo Zen em Naomi Kawase. In: XVIII Congresso de Ciências da Comunicação na Região Sudeste - São Paulo, 2013. Anais... São Paulo: Intercom.

Maia, Carla; Mourão, Patrícia (org.). 2011. O cinema de Naomi Kawase. Rio de Janeiro: CCBB RJ.

Marks, Laura U. 2000. The skin of the film: Intercultural cinema, embodiment, and the senses. Duke University Press.

Oliveira, Eduardo dos Santos. 2015. Diante de um transbordamento: anotações sobre o cuidado em Carta de uma Cerejeira Amarela em Flor. In: XXXVIII Congresso Brasileiro de Ciências da Comunicação - Rio de Janeiro 2015. Anais... Rio de Janeiro: Intercom.

—_—; Codato, Henrique. 2017. O arquivo cine-performático de Naomi Kawase. REVISTA PASSAGENS - Programa de PósGraduação em Comunicação da Universidade Federal do Ceará, v. 8, n. 2. 135-151.

Pick, Anat; Narraway, Guinevere. 2013. Screening nature: Cinema beyond the human. New York: Berghahn Books.

Plumwood, Val. 2002. Feminism and the Mastery of Nature. London; New York: Routledge.

Rancière, Jacques. 2012. O espectador emancipado. Tradução de Ivone C. Benedetti - São Paulo: Editora WMF Martins Fontes.

Tuan, Yi-Fu. 1980. Topofilia: um estudo da percepção, atitudes e valores do meio ambiente. São Paulo: Difel.

Vieira Jr. Erly. 2014. Corpo e cotidiano no cinema de fluxo contemporâneo. In: Revista Contracampo, v. 29, n. 1, Niterói: Contracampo, 109-130.

Willoquet-Maricondi, Paula. 2010. Framing the World: Explorations in Ecocriticism and Film. University of Virginia Press.

\section{FILMOGRAFIA}

Floresta dos lamentos (Mogari no Mori) [longa-metragem]. Dir. Naomi Kawase. Kumie. Japão, 2007. 97 mins.

O segredo das águas (Futatsume no Mado) [longa-metragem]. Dir. Naomi Kawase. Kumie. Japão, 2014. 121 mins. 